\title{
OPTIMAL DESIGN FOR A COMPOSITE WIND TURBINE BLADE WITH FATIGUE AND FAILURE CONSTRAINTS
}

\author{
Adam Chehouri $^{1,2}$, Rafic Younes ${ }^{1,3}$, Adrian Ilinca ${ }^{3}$, Jean Perron ${ }^{1}$ and Hassan Lakiss ${ }^{2}$ \\ ${ }^{1}$ Anti Icing Materials International Laboratory (AMIL), Université du Québec à Chicoutimi, Canada \\ ${ }^{2}$ Faculty of Engineering, Third Branch, Lebanese University, Rafic Harriri Campus, Hadath, Beirut, Lebanon \\ ${ }^{3}$ Wind Energy Research Laboratory (WERL), Université du Québec à Rimouski, Québec, Canada \\ E-mail: adam.chehouril@uqac.ca,rafic_younes@uqar.qc.ca,adrian_ilinca@uqar.ca, jean_perron@uqac.ca
}

Received January 2014, Accepted December 2014

No. 14-CSME-16, E.I.C. Accession Number 3677

\begin{abstract}
The search for more efficient and sustainable renewable energies is rapidly growing. Throughout the years, wind turbines matured towards a lowered cost-of-energy and have grown in rotor size therefore stretched the role of composite materials that offered the solution to more flexible, lighter and stronger blades. The objective of this paper is to present an improved version of the preliminary optimization tool called CoBlade, which will offer designers and engineers an accelerated design phase by providing the capabilities to rapidly evaluate alternative composite layups and study their effects on static failure and fatigue of wind turbine blades. In this study, the optimization formulations include non-linear failure constraints. In addition a comparison between 3 formulations is made to show the importance of choosing the blade mass as the main objective function and the inclusion of failure constraints in the wind turbine blade design.
\end{abstract}

Keywords: wind turbine, blade, optimization, failure, Co-Blade.

\section{CONCEPTION OPTIMALE D'UNE PALE D'ÉOLIENNE EN MATÉRIAUX COMPOSITES AVEC DES CONTRAINTES DE FATIGUE ET DE RUPTURE}

\section{RÉSUMÉ}

La recherche pour des énergies renouvelables plus efficaces et durables est en forte croissance. Au fil des années, les éoliennes ont acquis de la maturité avec un coût plus réduit et des tailles de rotor plus grandes élargissant ainsi l'utilisation des matériaux composites qui offrent plus de flexibilité, plus de légèreté et plus de solidité. L'objectif de cet article est de proposer une version améliorée du logiciel d'optimisation préliminaire Co-Blade, qui permettra aux concepteurs d'accélérer la phase de conception des pales d'éolienne en matériaux composites grâce à des outils d'études de diverses configuration des laminés composites et de leur comportements en rupture et en fatigue. Dans cette étude, les formules d'optimisation tiennent compte des contraintes de ruptures non linéaires. Additionnellement, une comparaison de 3 formules d'optimisation a été effectuée afin de mettre en évidence l'importance du choix de la masse tel que fonction objective principale et de la considération des contraintes de rupture dans la conception des pales d'éoliennes.

Mots-clés : éolienne; pale; optimisation; rupture; Co-Blade. 


\section{INTRODUCTION}

Advancements in the design of wind turbine blades are due to the exploration of more efficient structural and aerodynamic designs and the examination of optimal materials. The investigations and design evaluations of the materials and manufacturing issues for large wind turbine blades and rotors resulted in the design specifications and preliminary designs for candidate blades in the range of 30 to $70 \mathrm{~m}$ in length [1-3] and rotors in the range of 80 to $120 \mathrm{~m}$ in diameter $[4,5]$. Future designs that will tackle the design of even larger machines will continue to push the extremes of the design envelope, which is primarily limited by the penalty of weight growth. As pointed out by Veers et al. [6], improvements in blade design, manufacturing, and performance have always been a primary target of research. It has been shown that a 10-20\% decrease in blade weight may lead to a substantial reduction in the costs of other major elements such as the tower and the drive train, although wind turbine blades account for only $10-15 \%$ of the capital cost of the whole system. For that reason, in this paper we wish to focus on minimizing the blade mass of the wind turbine while satisfying structural, physical and design requirements.

Generally, a wind turbine blade is classified "successful" if certain objectives are met, some of which are in conflict. Therefore, the designers confront a multidisciplinary optimization problem. We can summarize the key objectives and constraints of wind turbine systems as follows [7]:

1. Maximize the annual energy for a given wind speed distribution.

2. Optimal power control, i.e. limit maximum power output.

3. Fatigue and extreme load resistance.

4. Minimize weight and cost.

5. Avoid resonances and blade/tower collisions.

The design process is divided in general into two stages: the aerodynamic design, in which objectives (1) and (2) are satisfied, and the structural design, where objectives (3) to (5) have to be met. The primary intent of previous optimization problems was to generate the furthermost rotational moment (or tangential force) for the given wind speed spectrum [8-10]. Other studies focused on shape optimization because the aerodynamic profiles of wind turbine blades have crucial influence on the aerodynamic efficiency of the wind turbine [11]. Conversely Jureczko et al. [12] demonstrated that pure aerodynamic optimization is insufficient when blades become longer than $45 \mathrm{~m}$ and the dynamic behavior becomes imperative, mainly because of the prominence of fatigue loads. Many studies attempted to reduce fatigue loads while generating sufficient power by dynamically controlling the blade pitch [7, 13-18]. Yet, additional restraints that aerodynamicist had and still have to consider are the public acceptance mainly from the generated noise by the wind turbine. Noise considerations are often of greater significance than energy capture in the decision of the speed of operation [7]. Other studies examined the elastic coupling in wind turbine blades in order to increase the captured power by aeroelastic tailoring [19-21]. Inevitably, there is an interaction between the aerodynamic and structural designs and hence an optimization issue arises.

An additional key element to wind energy performance optimization is obtained through effective strategies in order to reduce the power generation cost; this becomes an energy management problem. In this field, two research directions of wind turbines performance have been pursued, the first is the optimization of the performance of the wind turbine and second involves the optimization of the wind farm performance [11]. As stated by Zhang [11], the goal of single wind turbine optimization is to improve wind turbine efficiency and its life cycle, however, the performance optimization of a wind farm is to minimize the total cost of the wind farm operation threw active and adaptive scheduling strategies. Nevertheless, an optimization 
scheme must be set and solved for either goals but due to the complexity of the problems, which highlights the need of preliminary design result from a tool like the one we are proposing, for smaller computational time and better initial configurations for faster convergence. The reader is referred to Chehouri et al. [38] for a complete review of the performance optimization techniques and strategies applied to wind turbines; highlighting the main aspects such as: objective functions, design constraints, tools and models and optimization algorithms.

The current state of the art approaches for the structural analysis of composite blades are mainly based on finite element methods (FEM) such as in our previous work [17, 18]. It allows for utilization of complex geometric shapes, 3D and non-linear behavior, and extensive use of composite materials. However, FEM approaches become impractical for use in the preliminary design stages (where hundreds or potentially thousands of alternative designs may be evaluated) due to the labor-intensive task of generating accurate meshes and higher computational cost [22]. A software named Co-Blade developed by Danny Sale [23] for structural analysis of composite blades for wind turbines and hydrokinetic turbines is integrated in our optimization problem and served as the basis for our structural computation. Co-Blade computes span variant structural properties of composite blades and is a pre-processor for aeroelastic simulation codes (such as FAST [24], ADAMS, BLADED, etc.) that require these structural properties as inputs to model the major components of wind turbines. However, in this paper we choose to evaluate new objective functions which take account the fatigue and static failure constraints. A comparison between our suggested fitness function and the one proposed by Co-Blade is made for a wind turbine blade under the same design external loads. This will allow the design of blade for different lifetime with constraints formed by a fatigue model inspired from Hashin and Rotem [25] and a quadratic failure criterion: Tsai-Wu. Comparisons are made between the objective functions and the failure criterions to justify the use of a quadratic static failure criterion in our proposed minimization problem - the blade mass. Nevertheless our tool will enable the evaluation of the interaction between the structural and aerodynamic designs for enhanced optimal design. We begin by examining the description of Co-Blade by defining the blade geometry and composite layup, the technical approach and the optimization modes. We then inspect the blade optimization under failure and fatigue constraints. Lastly we discuss and conclude the results of the different optimization schemes.

\section{DESCRIPTION OF CO-BLADE}

In this section we present the methodology used within Co-Blade to compute structural properties and analysis. A combination of classical lamination theory (CLT) with an Euler-Bernoulli theory and shear flow theory applied to composite beams is used to perform the analysis. This approach allows for direct computation of the structural properties and analysis of a given blade, within several seconds of execution [23].

To further aid in the preliminary design of composite blades, Co-Blade proposed an optimization mode that can also optimize the layup of composite materials within the blade using three optimization algorithms (pattern search, gradient search and pattern swarm). For a given external blade shape and design load, Co-Blade presented a fitness function which minimizes the blade mass while simultaneously satisfying constraints on maximum stress, buckling, deflection, and placement of blade natural frequencies.

\subsection{Co-Blade Blade Geometry and Composite Lay-up}

Figure 1 illustrates an example of a composite blade (with an I-Beam and Box-Beam type layup, respectively) in which the primary bending loads are supported by the thick mid-sections (the spar caps) connected by one or more shear webs, and the aerodynamic shape is maintained by sandwich panels around the blade periphery [23]. These types of composite blades are often constructed with stacks of laminas having constant thickness, fiber orientation, and number of laminas around the cross section periphery; however, the number 


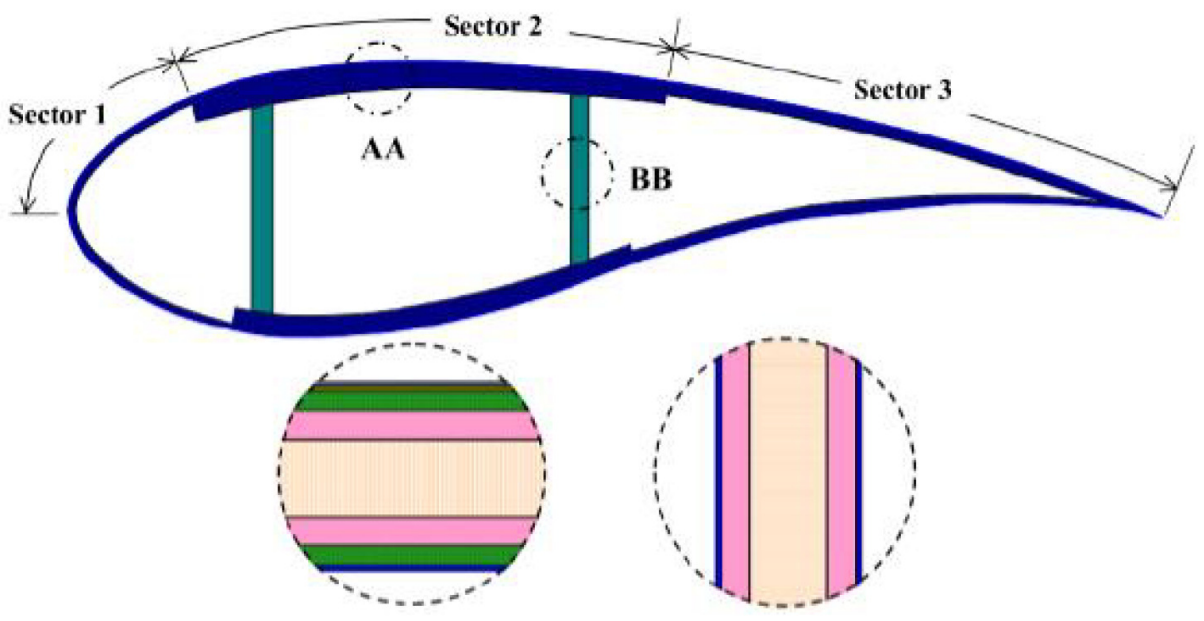

Fig. 1. An illustration of a composite blade cross section in Co-Blade. Image reproduced with permission from [39].

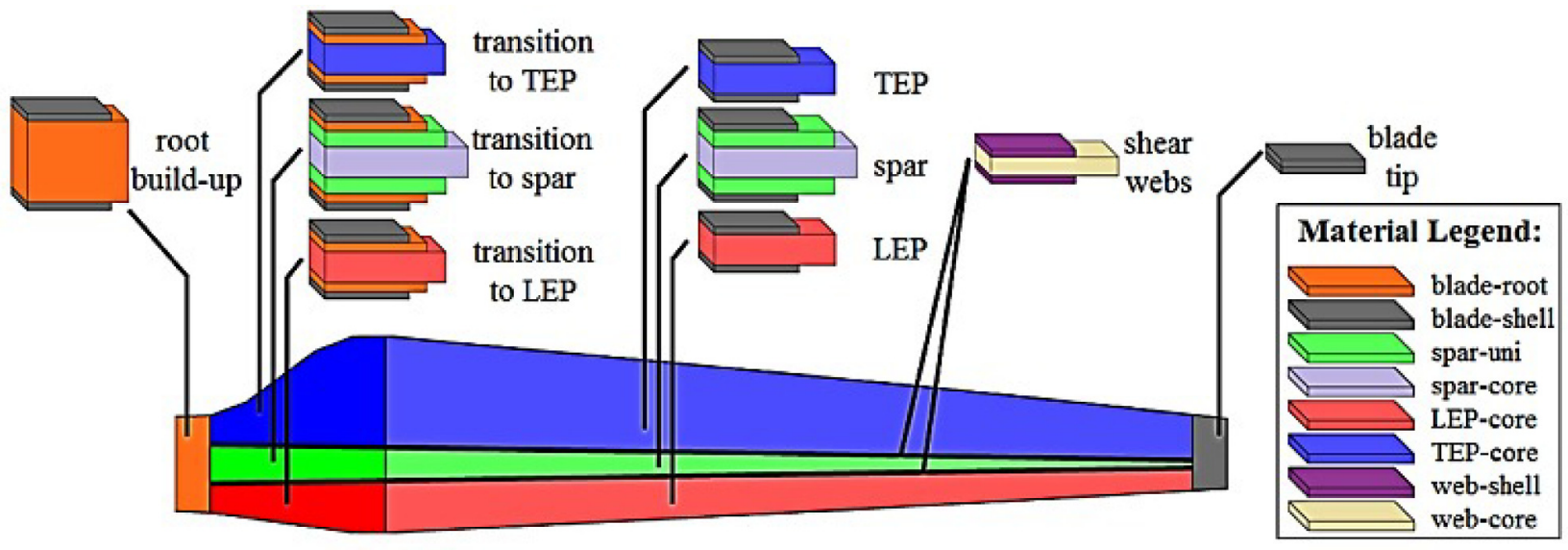

Fig. 2. An illustration of the composite layup when Co-Blade is in optimization mode. Image reproduced with permission from [23].

and thickness of the laminas will usually vary along the blade length. A single laminate is defined as a stack of laminas and the sequence, number, fiber orientation, and material of the individual laminas distinguish it. Co-Blade is capable of modeling complicated composite layups, such as the blades illustrated in Fig. 1. At what time Co-Blade is in analysis mode, it is possible to model a composite blade with arbitrary topology and material properties, such as the blade illustrated in Fig. 1. However, Co-Blade is required to make some stricter assumptions about the blade composite layup in order to run the problem in optimization. When Co-Blade runs in optimization mode, the layup of composite materials is restricted to the configuration illustrated in Fig. 2. As Fig. 2 shows, the blade is considered to consist of nine unique laminate schedules with eight materials, each material having its own unique mechanical properties predefined by the user. A description of the laminates within each section of the blade is as follows [23]:

- root build-up: This thick material is sandwiched between the "blade-shell" material. Near the maximum chord blade station, the "blade-root" material tapers off completely, and the thickness of the "blade-root" material is assumed to linearly decrease moving towards the maximum chord blade station. 
- leading edge panel (LEP): The material schedule is [blade-shell/blade-root/LEP-core $]_{s}$.

- trailing edge panel (TEP): The material schedule is [blade-shell/blade-root/TEP-core $]_{s}$.

- spar cap: The material schedule is [blade-shell/blade-root/spar-uni/spar-core $]_{s}$.

- shear web: The "web-core" material is sandwiched between the "web-shell" material.

- blade tip: at the blade tip, all other lamina plies have been assumed inexistent and only the "bladeshell" material exists. The "blade-shell" material covers both the interior and exterior surfaces of the top and bottom blade surfaces along the entire length of the blade.

In optimization mode, it is important to mark that the laminate schedules and chordwise subdivisions of laminates are identical on the top and bottom blade surfaces, and the laminates that make the shear webs are identical to each other. A limitation of the current version of Co-Blade is that all laminates are considered balanced and symmetrical, eliminating the possibility for cross-coupled stiffnesses.

The design variables are the chordwise width of the spar cap at the inboard and outboard locations, the thickness of the "blade-root" material, and the thicknesses of the laminas within the LEP, TEP, spar cap, and shear webs along the length of the blade. They are listed in Table 1.

\subsection{Co-Blade Technical Approach}

The theory implemented within Co-Blade is based upon a combination of classical lamination theory (CLT) with an Euler-Bernoulli theory and shear flow theory applied to composite beams. At first, the blade is represented as a cantilever beam under the influence of flapwise and edgewise bendings, axial deflection, and elastic twist. Additional coupling between bending, extension, and torsion are accounted for, due to the offsets of between the beam shear center, tension center, and center of mass from the blade pitch axis. The beam cross sections are assumed thin-walled, closed, and single or multi-cellular and the periphery of each beam cross section is discretized as a connection of flat composite laminates.

The classical lamination theory can be viewed and is well described in [26, 27]. Classical lamination theory is more general than laminated beam theory since it includes extensional, flexural and torsional deformations. Coupling effects between bending/twisting, bending/extension, twisting/extension are included. The CLT theory assumes that each ply is in plane stress.

Regarding Euler-Bernoulli beam theory, Co-Blade treats the beam cross sections as heterogeneous and each of the material properties depend on the location in each cross section. The structural analysis at each discrete portion of the composite beam characterizes effective mechanical properties computed via classical lamination theory. Each discrete portion of the cross section then contributes to the global section properties of the composite beam (described in more detail in $[28,29]$ ). Once the global cross sectional properties are calculated, the deflections and effective beam axial stress $\left(\sigma_{z z}\right)$ and effective beam shear stress $\left(\tau_{z s}\right)$ can be now computed under the assumptions of an Euler-Bernoulli beam (refer to [28-30]). The calculation of $\tau_{z s}$, prediction of shear center and torsional stiffness are based on a shear flow approach, which is discussed in details in [30].

Finally, by converting the distribution of effective beam stresses $\sigma_{z z}$ and $\tau_{z s}$ into equivalent inplane loads (as shown in Fig. 3), the lamina-level strains and stresses in the principal fiber directions $\left(\varepsilon_{11}, \varepsilon_{22}, \gamma_{12}, \sigma_{11}, \sigma_{22}\right.$ and $\left.\tau_{12}\right)$ can be evaluated using CLT.

\subsection{Co-Blade Optimization Mode}

When Co-Blade is in optimization mode, for a given external blade shape and design load, Co-Blade will vary the location and thickness of the materials in order to minimize the proposed fitness function $f(\mathbf{x})$. This 
Table 1. Optimization design variables of Co-Blade. Table reproduced with permission from [23].

\begin{tabular}{|c|c|}
\hline Parameter & Description \\
\hline w_cap_inb, w_cap_oub & $\begin{array}{l}\text { width of the spar cap normalized by the chord length at the INB_STN and } \\
\text { OUB_STN blade stations }\end{array}$ \\
\hline t_blade_root & thickness of the "blade-root" material at the INB_STN blade station \\
\hline t_blade_skin $1 . . . t$ t_blade_skinN & $\begin{array}{l}\text { thickness of "blade-shell" material at control points } 1 \text { through NUM_CP. The } \\
\text { control points are equally spaced along the blade between the TRAN_STN and } \\
\text { OUB_STN blade stations }\end{array}$ \\
\hline t_cap_uni1 ...t.t_cap_uniN & thickness of "spar-uni" material at control points 1 through NUM_CP \\
\hline t_cap_core1...t_cap_coreN & thickness of "spar-core" material at control points 1 through NUM_CP \\
\hline t_lep_core1...t_lep_coreN & thickness of "LEP-core" material at control points 1 through NUM_CP \\
\hline t_tep_core1...t_tep_coreN & thickness of "TEP-core" material at control points 1 through NUM_CP \\
\hline t_web_skin1, t_web_skin2 & $\begin{array}{l}\text { thickness of "web-shell" material at the two control points located at INB_STN } \\
\text { and OUB_STN }\end{array}$ \\
\hline t_web_core1, t_web_core2 & $\begin{array}{l}\text { thickness of "web-core" material at the two control points located at INB_STN } \\
\text { and OUB_STN }\end{array}$ \\
\hline w_cap_inb, w_cap_oub & $\begin{array}{l}\text { width of the spar cap normalized by the chord length at the INB_STN and } \\
\text { OUB_STN blade stations }\end{array}$ \\
\hline t_blade_root & thickness of the "blade-root" material at the INB_STN blade station \\
\hline t_blade_skin $1 . . . t$ t_blade_skinN & $\begin{array}{l}\text { thickness of "blade-shell" material at control points } 1 \text { through NUM_CP. The } \\
\text { control points are equally spaced along the blade between the TRAN_STN and } \\
\text { OUB_STN blade stations }\end{array}$ \\
\hline t_cap_uni1 ...t_cap_uniN & thickness of "spar-uni" material at control points 1 through NUM_CP \\
\hline t_cap_core1...t_cap_coreN & thickness of "spar-core" material at control points 1 through NUM_CP \\
\hline t_lep_core1...t_lep_coreN & thickness of "LEP-core" material at control points 1 through NUM_CP \\
\hline
\end{tabular}
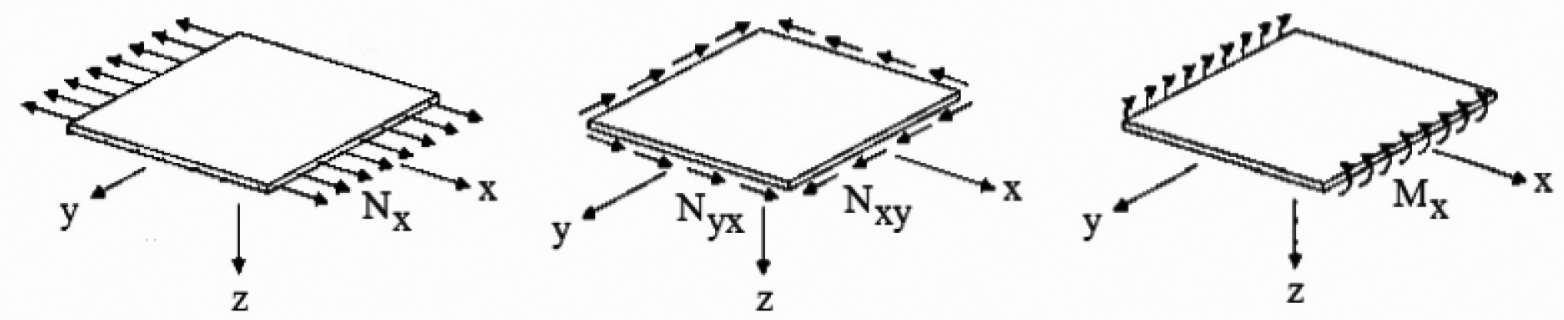

Fig. 3. Conversion of the effective beam stresses from Euler-Bernouilli theory and recovery of the strains and stresses [23].

function is set to minimize the blade mass while satisfying constraints on maximum stress, buckling, tip deflection, and separation of the blade natural frequencies from the blade rotation frequency. Mathematically, this optimization problem is formulated in the user's guide as follows: 
Table 2. Mechanical properties of the utilized materials [1].

\begin{tabular}{cccccc}
\hline$E_{11}(\mathrm{~Pa})$ & $E_{22}(\mathrm{~Pa})$ & $G_{12}(\mathrm{~Pa})$ & $v_{12}$ & $\rho\left(\mathrm{kg} / \mathrm{m}^{3}\right)$ & Material Name \\
\hline $2.80 \mathrm{E}+10$ & $1.40 \mathrm{E}+10$ & $7.00 \mathrm{E}+09$ & 0.4 & 1850 & (blade-root) \\
$2.80 \mathrm{E}+10$ & $1.40 \mathrm{E}+10$ & $7.00 \mathrm{E}+09$ & 0.4 & 1850 & (blade-shell) \\
$4.20 \mathrm{E}+10$ & $1.40 \mathrm{E}+10$ & $3.00 \mathrm{E}+09$ & 0.28 & 1920 & (spar-uni) \\
$2.60 \mathrm{E}+08$ & $2.60 \mathrm{E}+08$ & $2.00 \mathrm{E}+07$ & 0.3 & 200 & (spar-core) \\
$2.60 \mathrm{E}+08$ & $2.60 \mathrm{E}+08$ & $2.00 \mathrm{E}+07$ & 0.3 & 200 & (LEP-core) \\
$2.60 \mathrm{E}+08$ & $2.60 \mathrm{E}+08$ & $2.00 \mathrm{E}+07$ & 0.3 & 200 & (TEP-core) \\
$1.40 \mathrm{E}+10$ & $1.40 \mathrm{E}+10$ & $1.20 \mathrm{E}+10$ & 0.5 & 1780 & (web-shell) \\
$2.60 \mathrm{E}+08$ & $2.60 \mathrm{E}+08$ & $2.00 \mathrm{E}+07$ & 0.3 & 200 & (web-core) \\
\hline
\end{tabular}

$$
\begin{aligned}
\text { Minimize } f(\mathbf{x}) & =\text { Blade Mass } \cdot \Pi_{n=1}^{8} \max \left(1, p_{n}\right)^{2} \\
p_{1} & =\frac{\sigma_{11, \text { max }}}{\sigma_{11, f_{T}}} \\
p_{2} & =\frac{\sigma_{11, \text { min }}}{\sigma_{11, f_{C}}} \\
p_{3} & =\frac{\sigma_{22, \text { max }}}{\sigma_{22, f_{T}}} \\
p_{4} & =\frac{\sigma_{22, \min }}{\sigma_{22, f_{C}}} \\
p_{5} & =\frac{\left|\tau_{12, \text { max }}\right|}{\tau_{12, y}} \\
p_{6} & =\left(\frac{\sigma}{\sigma_{\text {buckle }}}\right)^{\alpha}+\left(\frac{\tau}{\tau_{\text {buckle }}}\right)^{\beta} \\
p_{7} & =\frac{\text { Tip Deflection }}{\text { Max Tip Deflection }} \\
p_{8} & =\max \left\{\frac{m i n \text { allowable diff. between rotor freq. and the blade naturel freq. }}{\left|\omega_{m}-\omega_{\text {rotor }}\right|},\right.
\end{aligned}
$$

Subject to:

$$
\begin{aligned}
& \mathbf{x}_{L B} \leq \mathbf{x} \leq \mathbf{x}_{U B} \quad \text { (lower and upper bounds) } \\
& A \mathbf{x} \leq \mathbf{b} \quad \text { (linear constraint). }
\end{aligned}
$$

During both the structural analysis and the optimization mode, the nine unique laminate schedules are formed with a total of eight possible materials (where each material can have its own unique properties defined). In our study, these properties are derived from Sandia $100 \mathrm{~m}$ blade SNL-100 [1]. Table 2 lists the mechanical properties utilized in the structural design of the blade.

\section{OPTMIZATION WITH FAILURE CONSTRAINTS}

The fitness function formulated by Co-Blade is composed of the product of all eight penalties with the blade mass. In other words, their blade mass minimization problem is "tampered" by the exceeded constraints, 
making the objective function linearly depend on them. If we take a look at the constraints $p_{1}$ to $p_{5}$, we notice that they are based on the "maximum stress failure envelope". Failure is predicted in a lamina, if any of the normal or shear stresses in the local axes of a lamina is equal to or exceeds the corresponding ultimate strengths of the unidirectional lamina therefore this criterion ignores the interaction of stresses. For this reason, our motive in this section is to introduce a quadratic failure criterion such as the Tsai-Wu failure criteria from Eq. (2) for anisotropic materials [31] in our proposed optimization scheme.

$$
f_{1} \sigma_{1}+f_{2} \sigma_{2}+f_{11} \sigma_{1}^{2}+f_{22} \sigma_{2}^{2}+f_{66} \tau_{6}^{2}+2 f_{12} \sigma_{1} \sigma_{2}=1 \text {. }
$$

where $f_{i j}$ and $f_{i}$ are constants that can be evaluated at boundary conditions. Their expressions can be found in detail in [31].

We define our main objective as the minimization of the blade mass solely. However, the Tsai-Wu failure criterion is dependent of the principal stresses, which is itself function of the design variables of Table 1 . Hence, the failure criteria in our case the Tsai-Wu failure criterion is a nonlinear constraint and the formulation of such minimization problem can now be described as

Minimize $f(\mathbf{x})=$ Blade Mass

Subject to:

$\mathbf{x}_{L B} \leq \mathbf{x} \leq \mathbf{x}_{U B} \quad$ (lower and upper bounds)

$A \mathbf{x} \leq \mathbf{b} \quad$ (linear constraint)

With the additional nonlinear constraints:

Tsai-Wu $(\mathbf{x})-1 \leq 0$

$\left(\frac{\sigma}{\sigma_{\text {buckle }}}\right)^{\alpha}+\left(\frac{\tau}{\tau_{\text {buckle }}}\right)^{\beta}-1 \leq 0$

$\frac{\text { Tip Deflection }}{\text { Max Tip Deflection }}-1 \leq 0$

$\max \left\{\frac{\text { Min. diff. between rotor freq. and the blade natural freq. }}{\left|\omega_{m}-\omega_{\text {rotor }}\right|}\right\}-1 \leq 0 \quad m=1, \ldots$, Modes

Let us consider at first a comparison between the two optimization problems presented above in Eqs. (1) and (3). We choose a $100 \mathrm{~m}$ long blade SNL-100 [3], discretized into 34 sections with varying airfoils shapes along the blade length. The Matlab function fmincon takes the matrix $\mathbf{A}$, the vectors $\mathbf{b}$ and boundary conditions along with the nonlinear constraints as inputs, and the optimization problem is solved using a gradient based approach (GBA). We assume four control points; giving a total of 27 design variables. Initial values are estimated using empirical formulas relating the thicknesses in Table 1, with the geometry of the blade.

From the first optimization problem as per Eq. (1), after 17 iterations with 1017 evaluations, a blade mass of $44186 \mathrm{~kg}$ is obtained. If we consider our optimization problem introduced in Eq. (3), after 45 iterations with 2700 evaluations, we obtain a total blade mass of $72348 \mathrm{~kg}$ (Fig. 4). A much more realistic blade mass (30\% more than the first mass) is obtained, according to the predicted blade mass for SNL-100 as per Jackson et al. [3]. The Tsai-Wu failure criterion written in Eq. (2) permits the evaluation of a "static failure" variable $\mathbf{f}$. The value of $\mathbf{f}$ can be greater or less than one. If its value exceeds one, it indicates that the composite component has reached static failure. 


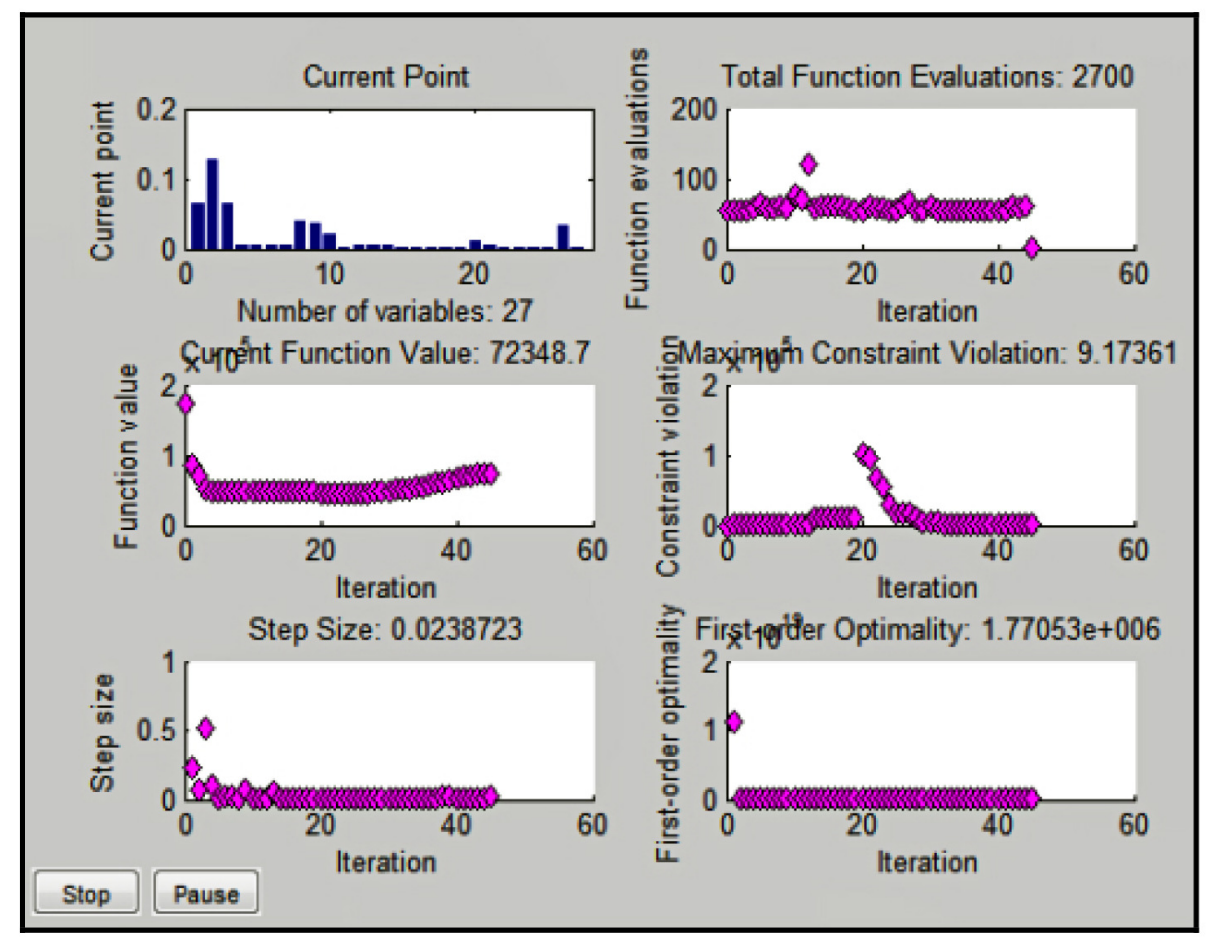

Fig. 4. Optimization results for the formulation in Eq. (3).

In the two previous simulation results, a comparison between two different objective function formulations was made. However an additional study can be carried out to show the effectiveness of our minimization formulation under the quadratic failure constraint in contrast of that written in Eq. (1) under the maximum stress theory, particularly with the advantage in stating the failure limits as nonlinear constraints rather than linearly depend. To show the difference between both interpretations, we modify the optimization problem of Eq. (3), by substituting the penalties to nonlinear constraints of the form $c(x)-1<0$. The mathematical formulation is

$$
\begin{aligned}
\text { Minimize } f(\mathbf{x})= & \text { Blade Mass } \\
& \text { Subject to : } \\
& \mathbf{x}_{L B} \leq \mathbf{x} \leq \mathbf{x}_{U B} \quad \text { (lower and upper bounds) } \\
& A \mathbf{x} \leq \mathbf{b} \quad \text { (linear constraint) } \\
& \text { With the additional nonlinear constraints : } \\
p_{1}= & \frac{\sigma_{11, \max }}{\sigma_{11, f_{T}}}-1<0 \\
p_{2}= & \frac{\sigma_{11, \min }}{\sigma_{11, f_{C}}}-1<0 \\
p_{3}= & \frac{\sigma_{22, \max }}{\sigma_{22, f_{T}}}-1<0 \\
p_{4}= & \frac{\sigma_{22, \min }}{\sigma_{22, f_{C}}}-1<0
\end{aligned}
$$


Table 3. Obtained blade masses for all three optimization formulations.

\begin{tabular}{ccccc}
\hline $\begin{array}{c}\text { Optimization } \\
\text { formulation }\end{array}$ & $\begin{array}{c}\text { Objective function } \\
f(x)=\text { Blade mass? }\end{array}$ & $\begin{array}{c}\text { Nonlinear } \\
\text { constraints? }\end{array}$ & $\begin{array}{c}\text { Tsai-Wu } \\
\text { criterion? }\end{array}$ & Blade mass (kg) \\
\hline$(1)$ & $\mathrm{X}$ & $\mathrm{X}$ & $\mathrm{X}$ & 44,186 \\
$(3)$ & $\checkmark$ & $\checkmark$ & $\checkmark$ & 72,348 \\
$(4)$ & $\checkmark$ & $\checkmark$ & $\mathrm{X}$ & 55,528 \\
\hline
\end{tabular}

$$
\begin{aligned}
p_{5} & =\frac{\left|\tau_{12, \text { max }}\right|}{\tau_{12, y}}-1<0 \\
p_{6} & =\left(\frac{\sigma}{\sigma_{\text {buckle }}}\right)^{\alpha}+\left(\frac{\tau}{\tau_{\text {buckle }}}\right)^{\beta}-1<0 \\
p_{7} & =\frac{\text { Tip Deflection }}{\text { Max Tip Deflection }}-1<0 \\
p_{8}= & \max \left\{\frac{\text { Min allowable diff. between rotor freq. and the blade natural freq. }}{\left|\omega_{m}-\omega_{\text {rotor }}\right|}\right\}-1<0 \\
& m=1, \ldots, \text { Modes }
\end{aligned}
$$

After 44 iterations with 2730 evaluations we obtain a blade mass of $55528.7 \mathrm{~kg}$. This means that a larger blade mass from that of Eq. (1) is obtained, however it is remarkably smaller than the blade mass from the optimization formulation under the quadratic failure constraint of Eq. (3). In summary, we can reproduce the results for the optimizations under failure constraints as shown in Table 3.

\section{OPTMIZATION WITH FATIGUE AND FAILURE CONSTRAINTS}

Wind turbines are fatigue critical machines and the design of many of their components, in particular the blades, are dictated by fatigue considerations [32]. Several factors are responsible to the fatigue phenomena of the wind turbine blades which can be summarized as shown below [33]:

1. Flexible and long structures.

2. Vibrations during the resonant mode.

3. Randomness in the load spectra due to the nature of the wind.

4. Continuous operation under varying conditions.

5. Low maintenance during lifetime.

A wind turbine blade is designed to sustain its mission for about 20-30 years. Figure 5 shows a comparison between different industrial components and their expected life cycles. The aforementioned reasons cause structural design constraints that must be included in the optimization scheme. For the case of extreme load design, the load estimation is usually limited to finding a single maximum load level that the structure can tolerate [32]. As for the design against fatigue, loads are defined for all input conditions and then summed and weighted by the relative frequency of occurrence [32]. Henceforward, in this section we wish to include both static and fatigue failures in the optimization scheme and evaluate its effect on the optimal design variables.

Degrieck and Van Paepegem [34] classified fatigue models into three major categories: fatigue life models (solely introduce a fatigue failure criterion), residual stiffness/strength models and finally progressive 


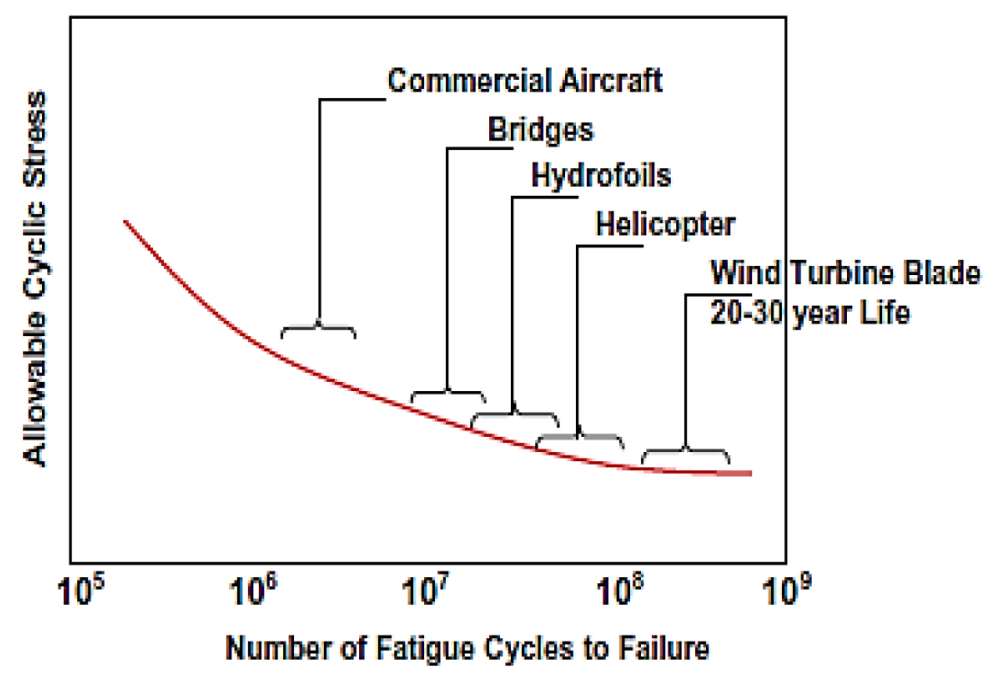

Fig. 5. Schematic S-N curves for different industrial components [33].

damage models. Defining a fatigue model that will correctly simulate the fatigue behavior of the wind turbine blade is not an easy task. In fact much of the ongoing research in that field is based on experimental or semi-empirical formulations. The first step before writing the fatigue failure criterion is to outline our case study in order to make some reasonable and acceptable assumptions. We begin by marking that in our study we are only considering unidirectional laminates subjected to an aerodynamic loading.

If we consider the weakest region in the blade that is showing the highest Tsai-Wu static failure variable f, we notice that the stress along the fibers is near 1000 times that of the transverse stress. This can be justified by assuming that in our external loading case, the blade is mostly sustaining the bending moment in the flapwise direction, which causes the blade to bendin the upwind/downwind direction.

Hashin and Rotem [25] proposed one of the first fatigue life models distinguishing two failure modes: a fibre-failure criterion and a matrix-failure mode. It is formulated by the following two equations:

$$
\sigma_{A}=\sigma_{A}^{U}, \quad\left(\frac{\sigma_{T}}{\sigma_{T}^{U}}\right)^{2}+\left(\frac{\tau}{\tau^{U}}\right)^{2}=1,
$$

where $\sigma_{A}$ and $\sigma_{T}$ are the stresses along the fibres and transverse to the fibres, $\tau$ is the shear stress and $\sigma_{A}^{U}, \sigma_{T}^{U}$ and $\tau^{T}$ are the ultimate tensile, transverse tensile and shear stress, respectively. Since the ultimate strength are function of the stress ratio $\mathbf{R}$, frequency $\mathbf{f}$ and the fatigue stress level, these ultimate strengths are replaced by their respective $\mathrm{S}-\mathrm{N}$ curves which must be determined experimentally. This criterion is only valid for unidirectional plies.

Assuming that the transverse stress is negligible to the shear and fibre stresses, we than obtain the form of two S-N curves, the first relative to longitudinal stress (along the fibres) and the second is for the shear stresses given by

$$
\begin{aligned}
\sigma_{A} & =\sigma_{A}^{U}, \\
\tau & =\tau^{U}
\end{aligned}
$$

Under the previous equations and further assuming that the two stresses are under the same loading conditions (stress ratio and cycling frequency), we perform our optimization problem from Eq. (3) with the addition of the proposed fatigue model. 
Rewriting a similar quadratic criterion inspired from to the Tsai-Wu criteria we can assume the following general form

$$
a \sigma_{A}+b \sigma_{A}^{2}+c \tau^{2}=1
$$

Under the boundary conditions of $\sigma=\sigma_{A}^{U}, \tau=0$ and $\sigma=-\sigma_{A}^{U}, \tau=0$, we obtain $a=0$ and $b=1 /\left(\sigma_{A}^{U}\right)^{2}$. Under the loading of $\left(\sigma=0, \tau=\tau^{U}\right)$, we obtain $c=1 /\left(\tau^{U}\right)^{2}$. Finally the full optimization problem includes the "lifetime" model represented by Eq. (6), can be rewritten in Eq. (7). Under the assumption made in Eq. (6), such multi-axial fatigue failure criterion can be deduced from the model proposed by Philippidis and Vassilopoulos [35], which is similar to the quadratic Tsai-Wu failure criterion. It is practical to include the constraints related to linear buckling, tip deflection and resonance to provide a more conclusive and substantial optimization quest.

Minimize $f(\mathbf{x})=$ Blade Mass

Subject to :

$\mathbf{x}_{L B} \leq \mathbf{x} \leq \mathbf{x}_{U B} \quad$ (lower and upper bounds)

$A \mathbf{x} \leq \mathbf{b} \quad$ (linear constraint)

With the additional nonlinear constraints :

$$
\begin{aligned}
& \text { Lifetime }(\mathbf{x})-1 \leq 0 \\
& \left(\frac{\sigma}{\sigma_{\text {buckle }}}\right)^{\alpha}+\left(\frac{\tau}{\tau_{\text {buckle }}}\right)^{\beta}-1 \leq 0 \\
& \frac{\text { Tip Deflection }}{\text { Max Tip Deflection }}-1 \leq 0 \\
& \max \left\{\frac{\text { Min diff. between rotor freq. and the blade natural freq. }}{\left|\omega_{m}-\omega_{\text {rotor }}\right|}\right\}-1 \leq 0 \quad m=1, \ldots, \text { modes. }
\end{aligned}
$$

The average simulation time for a typical optimization problem is 90 minutes on a $2.4 \mathrm{GHz}$ CPU. Multiple simulation cases were taken each having different lifetime input. Since wind turbines are subjected to a low cycling frequency [30], we assume a loading frequency of $1 \mathrm{~Hz}$. We consider the cases of three blade lifetime to failure: 3,30 and 300 years. The optimization tool will construct the optimal composite layups with the smallest blade mass possible satisfying our linear and nonlinear constraints.

Figure 6 shows the optimization window for the wind turbine blade with a three-years lifetime and a blade mass of $96584 \mathrm{~kg}$ is achieved. Whereas for more realistic lifetime expectancy such as 30 years, a blade mass of $121600 \mathrm{~kg}$ is found. It is important to note that such large blades have weights in the order of 100 tons, for wind turbines that have a nominal power of 13.5 MW. Finally, a wind turbine with a lifetime of 300 years is physically impossible to build, but it is vital to perform the simulation of such lifetime to validate the convergence of our algorithm.

\section{DISCUSSION}

The development of a failure criterion for composite materials has been pursued in the recent decades and there are countless theories available. A good review that summarizes the state of art in composite failure criterions is by Orifici et al. [36]. In [36], the failure criterions are categorized based on strength or fracture mechanics theories, failure mode prediction, or whether they focus on in-plane or interlaminar failure. Comparing the different failure criteria with each other for the purpose of our application - wind turbine blade - is a difficult task, which requires extensive experimental tests across the possible loading scenarios. 


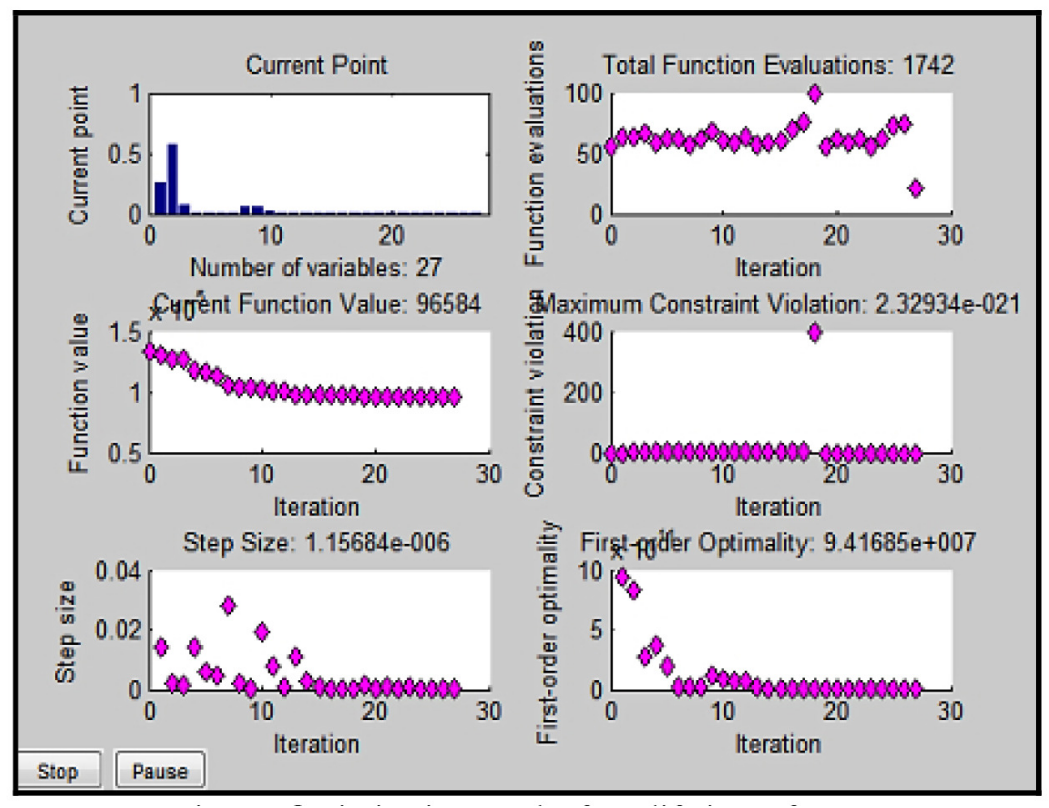

Fig. 6. Optimization results for a lifetime of three years.

The results of the optimization problem based on the fitness function employed by Co-Blade, written in Eq. (1) have showed that an "underestimated" blade mass is obtained and the purpose of our study was to present new optimization schemes that included failure and fatigue nonlinear constraints. This conclusion can be justified by the fact that the maximum stress failure theory under planar stress is a much larger area than the envelope of the quadratic failure of Tsai-Wu. Hence, satisfactory ratios in the maximum stress theory

$$
\left[\frac{\sigma_{11, \max }}{\sigma_{11, f T}}, \frac{\sigma_{11, \min }}{\sigma_{11, f C}}, \frac{\sigma_{22, \max }}{\sigma_{22, f T}}, \frac{\sigma_{22, \min }}{\sigma_{22, f C}}, \frac{\left|\tau_{12, \max }\right|}{\tau_{12, y}}\right] \text { equal to } 1
$$

form a stress tensor that produces definite failure under the Tsai-Wu criteria. Furthermore, the justification concerning the choice of the objective function and the use of a quadratic failure criterion can be viewed from the results of the formulation from Eq. (4). We found a more realistic blade in terms of the weight of the blade, however since it uses the maximum stress failure envelope, its blade mass is still underestimated in contrast of Eq. (3), where a quadratic failure criterion is employed.

We have considered the case for multiple wind blade lifetimes, with the obvious and predictable outcome that the larger the input lifetime, the larger the blade mass will be. However, it would be practical to include the imperative element - the cost. Assuming that one has designed a wind energy system that can reliably produce energy, one should be able to predict its annual energy production. The economic viability of wind energy depends on two variables: the market value of wind energy and the generating cost. Understandably, the market value of wind energy must exceed the cost before the purchase and design of a wind energy system can be economically justified. It is common practice to equate the design lifetime with the economic lifetime of a standard wind energy system such as a 20-year design lifetime [37]. In Europe, an economic lifetime of 20 years is often used for the economic assessment of wind energy systems (WEC, 1993). This follows the recommendations of the Danish Wind Turbine Manufacturers Association (1998) that state that a 20-year design lifetime is a suitable economic compromise that is used to guide engineers who develop components for wind turbines. Thus, it is evident that a constrained multi-disciplinary optimization with a cost of energy $(\mathrm{CoE})$ model is necessary for the development of a comprehensive tool for wind turbines. 
Nevertheless, it is not erroneous to consider the lifetime as an input defined by the manufacturer (e.g. 20 years), on the contrast of being directed by a cost function. The explanation of this statement resigns in the impact of wind energy - it has not matured enough to dominate the conventional energy sources (such as nuclear, fossil fuel power plants etc.) The main purpose of the use of wind energy is typically for environmental reasons, and it is justifiable that the manufacturer design the wind turbine blade to withstand the fatigue and static loads as long as possible during its lifetime - an endurance perspective.

\section{CONCLUSION}

In spite of all of the advancement in material science and composite materials in general, and in wind turbine blade specially, we have yet a great deal of research to be done. We have presented a preliminary structural analysis and optimization tool, capable of evaluating and designing composite layups and study their effects on the composite blade properties. Our code which was inspired from Co-Blade, demonstrated the advantage of writing the objective function as the blade mass solely along with an additional nonlinear constraint that characterize the static failure. This formulation resulted into much more realistic wind blade mass. Many assumptions were made in order to present a fatigue failure criterion, but it is reasonable to conclude that the algorithm showed promising results, in the hopes to fully validate by experimentation.

It would be interesting in the future to introduce a coupling between the structural optimization and the aerodynamic solver, with one component working as the objective and the other as a constraint. This will certainly be helpful for optimizing the blade performance over the full range of expected operating conditions (normal and extreme) by optimizing the blade geometry while simultaneously respecting the structural failure constraints. The reader is referred to [38] for a complete survey on performance optimization formulations and strategies applied to wind turbines.

Ultimately, the development of new architectures weaving broadens the scope of laminate composites. The multitude of complex architectures in terms of geometric poses firstly, the problem of predicting the mechanical behavior of these new materials and secondly the geometrical parameters that will provide the best compromise between cost - performance - mass. Wind turbine blades are an important application for this problem for the sake of producing clean energy with maximum efficiency and reduced mass of materials. Hence, we look forward to design a support system that will improve the optimization during the design and manufacture of the composite structure to reduce its volume and weight to the minimum necessary to ensure the required level of recycling or safe.

\section{ACKNOWLEDGEMENTS}

This work was supported by the LIMA \& AMIL Laboratory of the Université de Québec à Chicoutimi (UQAC) and the authors would like to thank the EDST of the Lebanese University for its financial contribution.

\section{REFERENCES}

1. Griffith, D.T. and Ashwill, T.D., The Sandia 100-Meter All-Glass Baseline Wind Turbine Blade: SNL100-00. Informe Técnico, Sandia National Laboratories, 2011.

2. Griffin, D.A., WindPACT Turbine Design Scaling Studies Technical Area 1 Composite Blades for 80-to 120Meter Rotor, Technical Report, National Renewable Energy Laboratory, NREL/SR-500-29492, Golden, CO. A.2.1, 2001.

3. Jackson, K., et al., "Innovative design approaches for large wind turbine blades", Wind Energy, Vol. 8, No. 2, pp. 141-171, 2005.

4. Griffin, D.A. and Ashwill, T.D., "Alternative composite materials for megawatt-scale wind turbine blades: design considerations and recommended testing", in Proceedings ASME 2003 Wind Energy Symposium, American Society of Mechanical Engineers, 2003. 
5. Hillmer, B., et al., "Aerodynamic and structural design of MultiMW wind turbine blades beyond 5MW", Journal of Physics: Conference Series, 2007.

6. Veers, P.S., et al., "Trends in the design, manufacture and evaluation of wind turbine blades", Wind Energy, Vol. 6, No. 3, pp. 245-259, 2003.

7. Burton, T., et al., Wind Energy Handbook, John Wiley \& Sons, 2011.

8. Thomas, A. and Lennart, S., "An overview of wind energy-status 2002", Renew Sustain Energy Review, Vol. 6, Nos. 1-2, pp. 67-128, 2002.

9. Joselin Herbert, G., et al., "A review of wind energy technologies", Renewable and Sustainable Energy Reviews, Vol. 11, No. 6, pp. 1117-1145, 2007.

10. Biegel, B., et al., "Wind turbine pitch optimization", in Proceedings 2011 IEEE International Conference on Control Applications (CCA), IEEE, 2011.

11. Zhang, Z., Performance Optimization of Wind Turbines, PhD Dissertation, University of Iowa, 2012, http://ir.uiowa.edu/etd/3024.

12. Jureczko, M., Pawlak, M. and Mezyk, A., "Optimisation of wind turbine blades", Journal of Materials Processing Technology, Vol. 167, Nos. 2-3, pp. 463-471, 2005.

13. Wang, H., Wang, W. and Bin, L., "Application of individual pitch controller for flicker reduction on variable speed wind turbines", in Proceedings Power and Energy Engineering Conference (APPEEC), 2010 Asia-Pacific, IEEE, 2010.

14. Nourdine, S., et al., "Comparison of wind turbine LQG controllers using individual pitch control to alleviate fatigue loads", in Proceedings 2010 18th Mediterranean Conference on Control \& Automation (MED), IEEE, 2010.

15. Xingjia, Y., et al., "Individual pitch control for variable speed turbine blade load mitigation", in Proceedings IEEE International Conference on Sustainable Energy Technologies (ICSET 2008), IEEE, 2008.

16. Jelavic, M., Petrovic, V. and Peric, N., "Individual pitch control of wind turbine based on loads estimation", in Proceedings 34th Annual Conference of IEEE Industrial Electronics (IECON2008), IEEE, 2008.

17. Chehouri, A., et al., A Comparative Study of Static and Fatigue Behaviors for Various Composite Orthotropic Properties for a Wind Turbine Using a Coupled FEM-BEM Method, GRIN Verlag, 2013.

18. Chehouri, A., et al., Advances in Composite Wind Turbine Blades: A Comparative Study, Anchor Academic Publishing, 2014.

19. Karaolis, N., Mussgrove, P. and Jeronimidis, G., "Active and passive aeroelastic power control using asymmetric fibre reinforced laminates for wind turbine blades", in Proceedings of the 10th British Wind Energy Conference, London, 1988.

20. Kooijman, H., Bending-Torsion Coupling of a Wind Turbine Rotor Blade, Netherlands Energy Research Foundation ECN, 1996.

21. Lobitz, D.W. and Veers, P.S., "Aeroelastic behavior of twist-coupled HAWT blades", in Proceedings ASME/AIAA Wind Energy Symposium, Reno, NV, 1998.

22. Sale, D., et al., "Structural optimization of composite blades for wind and hydrokinetic turbines", in Proceedings 1 st Marine Energy Technology Symposium, 2013.

23. Sale, D., User's Guide to Co-Blade: Software for Structural Analysis of Composite Blades, Northwest National Marine Renewable Energy Center, 2012.

24. Jonkman, J.M. and Buhl Jr., M.L., FAST User's Guide, National Renewable Energy Laboratory, Golden, CO, 2005.

25. Hashin, Z. and Rotem, A., "A fatigue failure criterion for fiber reinforced materials", Journal of Composite Materials, Vol. 7, No. 4, pp. 448-464, 1973.

26. Daniel, I.M., et al., Engineering mechanics of composite materials. Vol. 2006. 1994: Oxford university press New York.

27. Kaw, A.K., Mechanics of Composite Materials, CRC Press, 2005.

28. Rivello, R.M., Theory and Analysis of Flight Structures, https://code.google.com/p/co-blade/ downloads/detail?name=Co-Blade\%20Users\%20Guide\%20v1.20.00.pdf, McGraw-Hill, New York, 1969.

29. Allen, D.H. and Haisler, W.E., Introduction to Aerospace Structural Analysis, Wiley, 1985.

30. Bauchau, O.A. and Craig, J.I., Structural Analysis: With Applications to Aerospace Structures, Vol. 163, Springer, 2009. 
31. Tsai, S.W. and Wu, E.M., "A general theory of strength for anisotropic materials", Journal of Composite Materials, Vol. 5, No. 1, pp. 58-80, 1971.

32. Shokrieh, M.M. and Rafiee, R., "Simulation of fatigue failure in a full composite wind turbine blades", Composite Structures, Vol. 74, No. 3, pp. 332-342, 2006.

33. Sutherland, H., On the Fatigue Analysis of Wind Turbines, Sandia National Laboratories, 1999.

34. Degrieck, J. and Van Paepegem, W., "Fatigue damage modeling of fibre-reinforced composite materials: Review", Applied Mechanics Reviews, Vol. 54, No. 4, pp. 279-300, 2001.

35. Philippidis, T.P. and Vassilopoulos, A.P., "Fatigue of composite laminates under off-axis loading", International Journal of Fatigue, Vol. 21, No. 3, pp. 253-262, 1999.

36. Orifici, A.C., Herszberg, I. and Thomson, R.S., "Review of methodologies for composite material modelling incorporating failure", Composite Structures, Vol. 86, Nos. 1-3, pp. 194-210, 2008.

37. Manwell, J. and McGowan, J., Wind Energy Explained-Theory, Design and Application, John Wiley \& Sons, 2008.

38. Chehouri, A., et al., "Review of performance optimization techniques applied to wind turbines", Applied Energy, Vol. 142, pp. 361-388, 2015.

39. G.S. Bir, User's Guide to PreComp: Pre-Processor for Computing Composite Blade Properties, NREL/TP-50038926, National Renewable Energy Laboratory, Golden, CO, 2005. 